\title{
Photoconductive Semiconductor Switch Technology for Short Pulse Electromagnetics and Lasers *
}

\author{
Fred J Zutavern, Guillermo M. Loubriel, Alan Mar, Harold P. Hjalmarson, \\ Wesley D. Helgeson, Martin W. O'Malley, and Gary J. Denison \\ Sandia National Laboratories, Albuquerque, New Mexico, 87185-1153
}

\section{Abstract}

High gain photoconductive semiconductor switches (PCSS) are being used to produce high power electromagnetic pulses for: (1) compact, repetitive accelerators, (2) ultra-wide band impulse sources, (3) precision gas switch triggers, (4) optically-activated firesets, and (5) high power optical pulse generation and control. High power, sub-nanosecond optical pulses are used for active optical sensors such as compact optical radars and range-gated/ballistic imaging systems. Following a brief introduction to high gain PCSS and its general applications, this paper will focus on PCSS for optical pulse generation and control.

PCSS technology can be employed in three distinct approaches to optical pulse generation and control: (1) short pulse carrier injection to induce gain-switching in semiconductor lasers, (2) electro-optical Q-switching, and (3) optically activated Q-switching. The most significant PCSS issues for these applications are switch rise time, jitter, and longevity. This paper will describe both the requirements of these applications and the most recent results from PCSS technology. Experiments to understand and expand the limitations of high gain PCSS will also be described.

\section{INTRODUCTION}

High gain PCSS technology is different than conventional PCSS. The optical energy required to activate a high gain PCSS is generally several orders of magnitude less than the energy required for a conventional PCSS of similar capabilities. However, avalanche carrier generation which produces high gain, also produces current filaments which can damage the switches, particularly at their semiconductor-metal interfaces (contacts) and reduce their longevity. Fortunately, contacts have been and are being developed which can handle the high current densities associated with these current filaments. Optical triggering schemes are also being used to produce many filaments in parallel to increase switch total current without increasing the local current density. Large individual PCSS and multiple PCSS operating in series and parallel have demonstrated that this technology can be produce gigawatt pulses with sub-nanosecond rise times. The latest switching properties which have been demonstrated with GaAs PCSS in the high gain mode are shown in table I. The physical understanding and practical development of these switches continue to expand and improve. Our present understanding and previous results have been described in many papers[1].

This paper will provide a brief discussion of PCSS switching properties and general applications, and then focus on optical pulse generation and control with PCSS technology. Specific electromagnetic pulse applications have been demonstrated and documented in internal reports[2,3]. Some of the optical pulse testing and applications have also been described previously[4,5]. Switching issues for short optical pulse generation and control and experiments to improve PCSS for this application will be summarized.

\section{SWITCHING PROPERTIES}

Probably the most useful property of high gain PCSS is optical triggering gain. Conventional (or linear) PCSS produces one electron-hole pair for each photon absorbed. With high gain PCSS, the optical trigger and a moderate electric field $(4-8 \mathrm{kV} / \mathrm{cm})$ induce avalanche carrier generation. In low impedance circuits, thousands of electron-hole pairs can be produced for each photon absorbed. This means that high gain PCSS require much less optical trigger energy than conventional PCSS.

Devices which depend upon avalanche carrier generation approach a steady-state with the formation of either current filaments or charge domains. The shape of the current-voltage (I-V) characteristic curve determines whether filaments or domains are formed. In GaAs PCSS, the I-V curve is "S-shaped" and images of high gain PCSS always show current filaments when optical triggering gain is evident $[6,7]$. Unfortunately, current filaments imply high carrier densities which can damage the switches and reduce their lifetimes. To deal with these high carrier densities, sub-surface, high conductivity contacts are being developed at SNL. This research effort has yielded gradual but steady improvement of roughly five orders of magnitude in device longevity over the last ten years[8].

The high gain PCSS switching properties, which have been achieved at SNL, are shown in Table I. These results are not necessarily the limits of the technology, but rather the best that have been demonstrated to date. Maximum voltage, current, and power were achieved on a bank of six wafers for thousands of shots by triggering approximately 200 independent filaments. The other

\footnotetext{
* Sandia National Laboratories is a multi-program laboratory operated by Sandia Corporation, a Lockheed Martin Company, for the United States Department of Energy under Contract DE-AC04-94AL85000.
} 


\section{DISCLAIMER}

This report was prepared as an account of work sponsored by an agency of the United States Government. Neither the United States Government nor any agency thereof, nor any of their employees, make any warranty, express or implied, or assumes any legal liability or responsibility for the accuracy, completeness, or usefulness of any information, apparatus, product, or process disclosed, or represents that its use would not infringe privately owned rights. Reference herein to any specific commercial product, process, or service by trade name, trademark, manufacturer, or otherwise does not necessarily constitute or imply its endorsement, recommendation, or favoring by the United States Government or any agency thereof. The views and opinions of authors expressed herein do not necessarily state or reflect those of the United States Government or any agency thereof. 


\section{DISCLAIMER}

Portions of this document may be illegible in electronic image products. Images are produced from the best available original document. 
results were not simultaneous. Lifetime results are for a single filament conducting $13 \mathrm{~A}$. Multiple filaments are used to achieve long lifetimes at higher total currents. Continuous repetition rate testing has been limited by the charging systems and can probably be much higher, although active cooling may be required.

Table I. High gain GaAs PCSS Properties

\begin{tabular}{|c|c|}
\hline maximum power & $650 \mathrm{MW}$ \\
\hline maximum voltage & $220 \mathrm{kV}$ \\
\hline maximum current & $8 \mathrm{kA}$ \\
\hline minimum trigger energy & $2 \mathrm{~nJ}$ \\
\hline maximum trigger gain & 100,000 \\
\hline maximum electric field & $100 \mathrm{kV} / \mathrm{cm}$ \\
\hline minimum rise time & $400 \mathrm{ps}$ \\
\hline minimum r-m-s jitter & $50 \mathrm{ps}$ \\
\hline max. continuous rep. rate & $1 \mathrm{kHz}$ \\
\hline max. burst rep. rate & $5 \mathrm{MHz}$ \\
\hline max. device lifetime & $50,000,000$ \\
\hline
\end{tabular}

\section{GENERAL APPLICATIONS}

The applications that have been proposed for high gain PCSS range from the very high power, short pulse switches needed for compact, high current, particle accelerators $(0.1-1.0 \mathrm{MV}, 50-500 \mathrm{kA})$ to the more modest devices required for Pockels cells $(0.3-2 \mathrm{kV}, 20 \mathrm{~A})$. Each application has unique requirements which take advantage of different PCSS properties and impact the design and development of a specific PCSS.

Short pulse, charged-particle accelerators which are compact, high current, and repetitive require high voltage, high current switches which can operate at $10-1000 \mathrm{~Hz}$. These goals can be achieved with banks of high gain PCSS producing many independent current filaments[3].

Impulse or ground penetrating radar require fast rise time, low jitter, and high power switches. With appropriate triggering, high gain PCSS can provide $0.5 \mathrm{~ns}$ rise time switches with $50 \mathrm{ps} r-\mathrm{m}$-s jitter to synchronize multiple sources of wide band electro-magnetic radiation.[2,9]

Precision gas switch triggers (figure 1) make use of low jitter, timing agility, optical isolation, and high voltage that is available with PCSS. Independent, optically isolated triggers provide design flexibility and the ability to continuously synchronize the gas switches as they age. Low voltage. or optical fiber control between the PCSS based triggers eliminate the need for a network of bulky high voltage trigger cables.

Firesets are capacitive discharge units that drive detonators for conventional and nuclear explosives. Desirable switching properties for these devices are optical isolation, DC stand-off, small size, low cost, low inductance, and radiation hardness. PCSS are being developed to provide smaller, more reliable, less expensive, optically-isolated replacements for the switches which are presently being used in firesets.

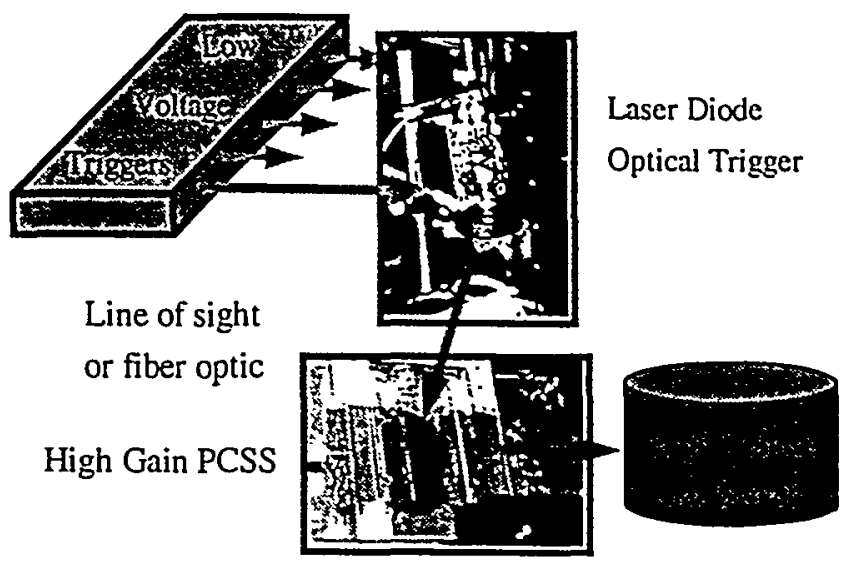

Figure 1. Block diagram of PCSS triggered gas switches.

Laser diode arrays (LDA) produce short optical pulses when carriers are injected into their junctions with subnanosecond electrical pulses. If the rise time of the electrical pulses is faster than $\sim 1 /$ bandwidth of the lasers, they will gain-switch (similar to Q-switching) and produce 10-75 ps long optical pulses. This electro-optical pulse compression can be used to make extremely small, high power, optical sources for active optical sensors such as pulsed optical radars and 3-dimensional imaging systems which can perform significantly better in optically obscured environments than long pulse or $\mathrm{CW}$ systems. LDAs have very low impedances (L), so system and switch inductance (L) must also be very low to produce fast rise times $(\sim \mathrm{L} / \mathrm{Z})$.

PCSS provide low inductance and fast rise times to gain switch large arrays of single heterojunction lasers which were widely produced in the 1970s and 1980s. However, the present rise time of our PCSS is not fast enough to gain-switch the higher bandwidth lasers which dominate the present commercial LDA inventories. The next section describes results from PCSS driven LDAs and experiments to determine switching requirements to gain switch higher bandwidth LDAs[4,5].

Pockels cells are electro-optical crystals that rotate the polarization of transmitted light. The amount of rotation depends upon the electric field across the cell, so when combined with a polarizer, they make electrically controlled optical switches with optical rise and fall times comparable to the electrical pulse. Almost all actively controlled short pulse solid state lasers use Pockels cells to make Q-switches, mode-lockers, and pulse selectors. Depending on their size, small cells typically require 300 $800 \mathrm{~V}$ to rotate the polarizaton $90^{\circ}$, so small PCSS can be used to provide sub-nanosecond rise time, low jitter pulses to drive the Pockels cells and synchronize advanced optical systems[10].

\section{OPTICAL PULSE GENERATION AND CONTROL}

As mentioned in the abstract and introduced in the previous section, there are three distinct ways to use PCSS for optical pulse modulation. 1) PCSS-driven, 
gain-switched LDA: very large arrays of wide-strip, single heterojunction lasers are gain-switched when pumped with a short, high-voltage pulse from the PCSS (figure 2). The individual lasers in the laser diode array (LDA) deliver approximately $100 \mathrm{~nJ}$ in $75 \mathrm{ps}$ wide pulses and we have produced total optical pulse energies as high as $44 \mu \mathrm{J}$. 2) PCSS-driven Pockels cells: the PCSS delivers a sub-nanosecond pulse to an electro-optical crystal which controls the lasing efficiency in laser cavities ranging from microchip microjoule lasers to table-top multi-Joule lasers. 3) PCSS-LDA bleached saturable absorbers: an optical pulse from a gain switched LDA (case 1) is used to bleach a saturable absorber which Q-switches and optical cavity. Bleaching the saturable absorber with a short optical pulse, produces a triggered, sub-nanosecond Q-switch from a passive Q-switch with multi-microsecond jitter (an optically controlled variation of case 2).

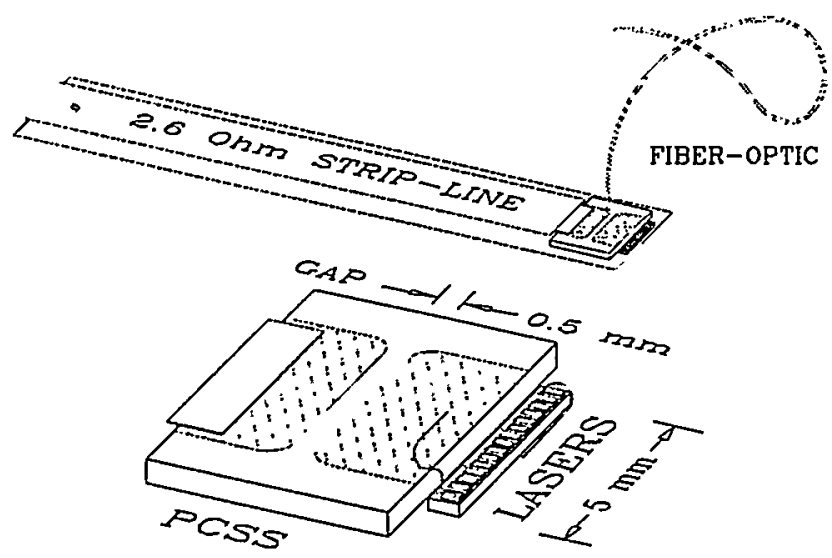

Figure 2. Enlargements of a PCSS-driven LDA.

Experimental testing has shown that single heterojunction (SHJ) LDAs give the best gain-switching (pulse compression) results with our present PCSS. The apparent explanation for this observation was that the delay between carrier injection and optical emission is longer for this type of laser than for other higher bandwidth, multi-quantum well (MQW) LDAs, which have better carrier confinement, lower lasing thresholds, and higher efficiency. If this explanation was valid, then faster switching rise time switches should be able to gain switch the higher bandwidth lasers.

Because the availability, lasing wavelengths, and efficiencies of the MQW LDAs are superior to the SHJ LDAs, experiments were performed to determine their switching requirements for gain-switching. Avalanche transitors cannot provide enough current or voltage to gain-switch large LDAs, but they can gain-switch individual or small arrays of laser diodes. A high speed pulser similar to the design reported by Fulkerson[11] based on avalanche transistors was assembled (figure 3 ), which produced $200 \mathrm{ps}$ rise time $100 \mathrm{~V}$ pulses on individual MQW lasers. An electrical pulses from this pulser with a $130 \mathrm{ps}$ rise time is shown in figure 4 . The optical output from a MQW laser is shown as a function

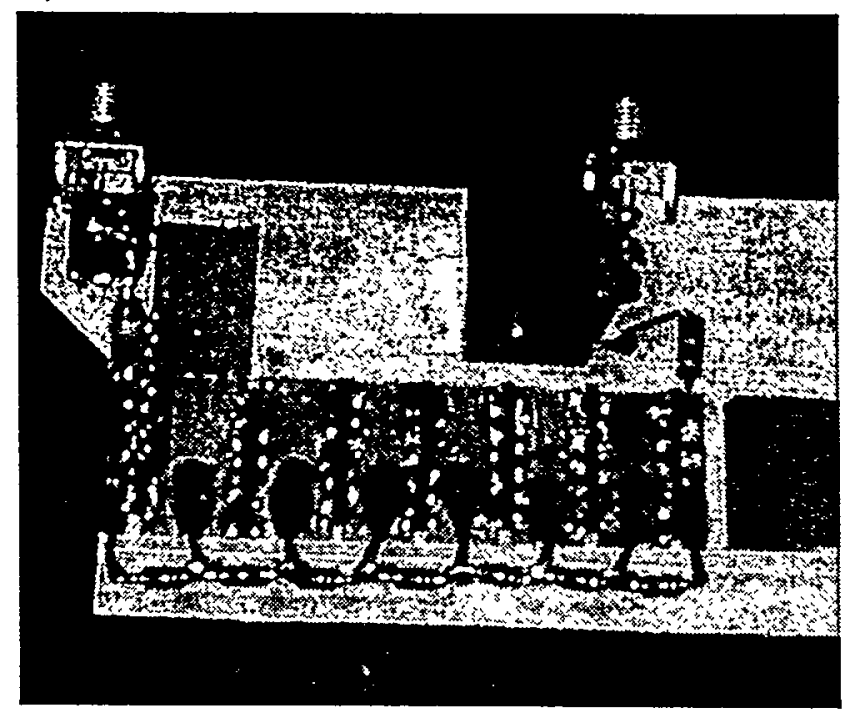

Figure 3. Picture of the circuit used to determine gainswitching requirements of individual MQW lasers.

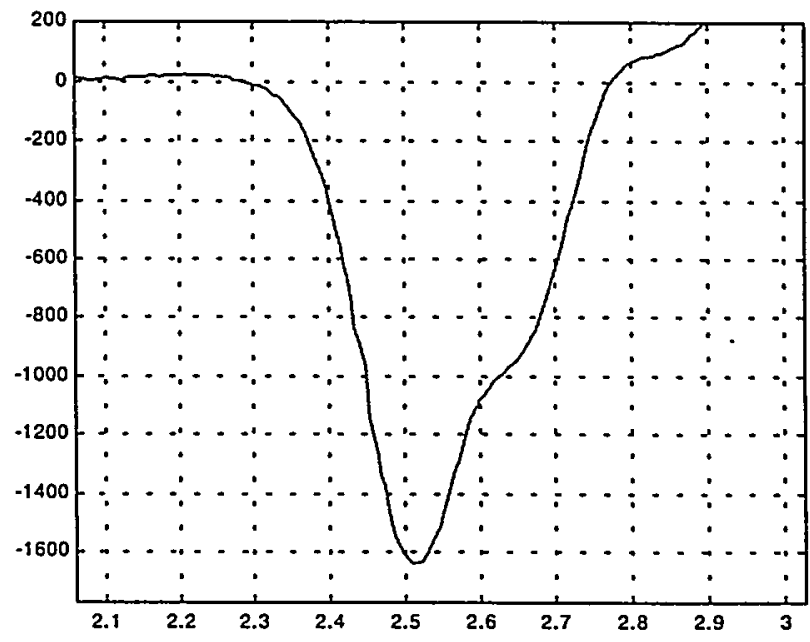

Figure 4. Electrical pulse gain-switching a MQW laser. Units are Volts vs. nanoseconds. Fall time is 130 ps.

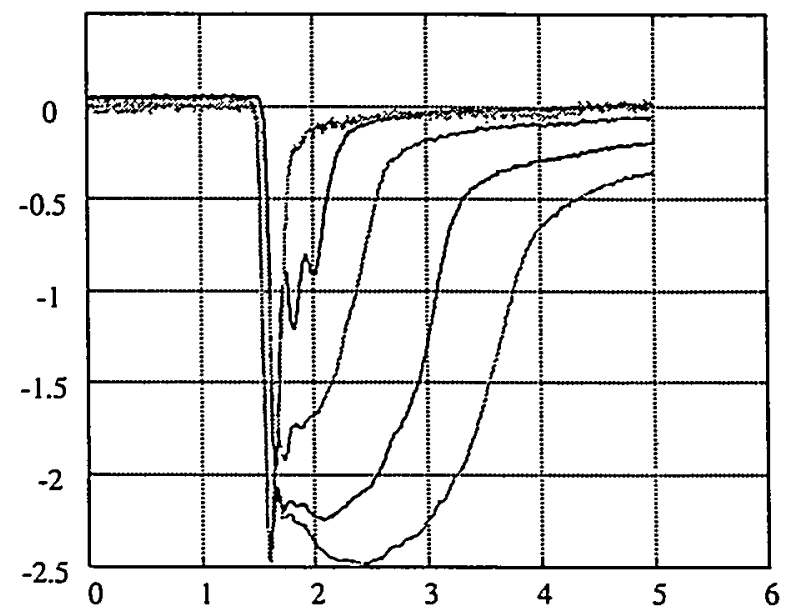

Figure 5. Optical pulses from a MQW laser as a function of increasing capacitance (4-33 pF). Units are Photodiode Volts vs. nanoseconds. 
of the driving capacitance in figure 5 . The narrowest optical pulse was obtained with $4.3 \mathrm{pF}$. Increasing capacitance put more optical energy into the tail of the pulse.

The best gain-switching results from these MQW lasers were observed when the electrical pulse rise time less than $150 \mathrm{ps}$ and the electrical pulse width was less than 250 ps. Slower rise time pulses do not induce gainswitching. Longer pulses produce multiple pulses (relaxation oscillations). Varying the pulser impedance changes the fraction of energy in the observed in the first pulse.

To gain-switch large MQW LDAs much higher currents and voltages must be delivered to the LDAs with these faster rise times. Roughly three avalanche transistors are required for each laser in the LDA. Since gain-switching LDAs with hundreds of lasers is desired, an avalanche-based pulser would require over a thousand high voltage transistors. A single high gain PCSS can deliver the required voltage and current, so experiments to find ways of decreasing the PCSS rise time from 400 to $150 \mathrm{ps}$ are being performed. Tests will include subnanosecond reactive feed-back to the PCSS and other pulse sharpening components such as ferrite transmission lines and delayed avalanche diodes used in conjunction with the PCSS.

\section{CONCLUSIONS}

PCSS technology provides many improved high power switching properties which can be used for a variety of high power, short pulse applications. Electromagnetic applications include gas switch replacements or triggers. Optical pulse generation and control is also achieved with fast rise time, low inductance LDAs or Pockels cell drivers. The specific advantages of the PCSS depend on the application and its requirements. The individual PCSS can be tailored to the application : longer switches for higher voltages $(200-220,000 \mathrm{~V})$, wider switches for higher currents $(1-8,000 \mathrm{~A})$, and longer lifetime with multiple filament optical triggering. Switching properties and device longevity continue to improve with continued research and development.

[1] See proceedings from the IEEE Pulse Power Conferences and IEEE Power Modulator Symposia, 1986-99, and

a.) A. Rosen and F. J. Zutavem, eds., High-Power Optically Activated Solid-State Switches, Artech House, Boston, 1993.

b.) G. M. Loubriel, F. J. Zutavern, H. P. Hjalmarson, R. R. Gallegos, W. D. Helgeson, and M. W. O'Malley, "Mensurement of the Velocity of Current Filaments in Optically Triggered. High Gain GaAs Switches", App. Phys. Let., Vol. 64, No. 24, 13 June, 1994, pp. 33233325.

c.) F. J. Zutavem. ed., Proc. SPIE Optically Activated Switching, Vol. 1378, Boston, MA, Nov., 1990.

d.) G. M. Loubriel. ed., Proc. SPIE Optically Activated Switching II, Vol. 1632, Los Angeles, CA. Jan., 1992. e.) R. A. Falk, ed., Proc. of SPIE Optically Activated Switching III, Vol. 1873. Los Angeles, CA., January, 1993.

f.) W. R. Donaldson, ed., Proc. of SPIE Oprically Activated Switching IV, Vol. 2343, Boston, MA. Oct.-Nov. 1994.

g.) G. M. Loubriel, F. J. Zutavern. A. G. Baca, H. P. Hjalmarson, T. A. Plut, W. D. Helgeson. M. W. O'Malley, M. H. Ruebush, and D. J. Brown, "Photoconductive Semiconductor Switches," IEEE Transactions on Plasma Science, Vol. 25. No. 2, April 1997, pp. 124- 130.

[2] Guillermo Loubriel, John Aurand, Malcolm Buttram, Fred Zutavern, Darwin Brown, and Wesley Helgeson, "Final Report of LDRD Project: Electromagnetic Impulse Radar for the Detection of Underground Structures," SNL Report SAND98-0724, Albuquerque, NM, 1998.

[3] F. J. Zutavern, M. W. O'Malley, M. H. Ruebush, L. F. Rinehart, G. M. Loubriel, S. R. Babcock, and G. J. Denison, "Final Report of LDRD Project: A Compact, Repetitive Accelerator for Military and Industrial Applications," SNL Report SAND98-0898, Albuquerque, NM, 1998.

[4] F. J. Zutavern, W. D. Helgeson, G. M. Loubriel, and M. W. O'Malley, "An Electro-optical Switching Amplifier (EOSA)", SNL Report, SAND 96-2923, Albuquerque, NM, 1996.

[5] F. J Zutavern, W. D. Helgeson, G. M. Loubriel, G. J. Yates, R. A. Gallegos, and T. McDonald, "A Compact, Short-pulse Laser for Near-field, Range-gated Imaging," Proc. SPIE 22nd Congress on High-Speed Photography and Photonics, Santa Fe, NM, 1996.

[6] H.P. Hjalmarson, K. Kambour, and C. W. Myles, "Collective Impact Ionization Theory of Lock-On" Proc. 12th IEEE Pulsed Power Conference, Monterey, CA, 1999.

[7]K. K. Kambour, C. W. Myles, H. P. Hjalmarson, "MonteCarlo Modeling of High Gain PCSS," Proc. 12th IEEE Pulsed Power Conference, Monterey, CA, 1999.

[8] A. Mar, A. G. Baca, D. J. Brown ,G. J. Denison, W. D. Helgeson, H. P. Hjalmarson, G. M. Loubriel, M. W. O'Malley, and F. J Zutavern, "Improved Longevity of Optically Activated, High Gain GaAs PCSS" Proc. 12 th IEEE Pulsed Power Conference, Monterey, CA, 1999.

[9] G. M. Loubriel, A. G. Baca, D. J. Brown ,G. J. Denison, W. D. Helgeson, H. P. Hjalmarson, A. Mar, M. W. O'Malley, and F. J Zutavern, "Ground Penetrating Radar" Proc. 12th IEEE Pulsed Power Conference, Monterey, CA, 1999.

[10] G. M. Loubriel, A. Mar, R. A. Hamil, F. J. Zutavern, and W. D. Helgeson, "Photoconductive Semiconductor Switches: Laser Q-Switch Trigger and Switch- Trigger Laser Integration," SNL Report SAND97-3111, Albuquerque, NM, 1997.

[11] E. S. Fulkerson, D. C. Norman, and R. Booth, "Driving Pockels Cells using Avalanche Transistor Pulsers," Proc. $11^{\text {th }}$ IEEE Pulsed Power Conf., Baltimore, MD. 1997, pp $1341-1346$. 